\title{
Forging Links Between Steelmaking and Nuclear Power
}

THE linking together of steelmaking and nuclear power is now a sufficiently real prospect, albeit ten years or more away, for representatives of European steel and nuclear companies to have decided in principle to form a club to look into the possibilities and problems more fully. This move was made at a discussion meeting, convened last week in London by the British Steel Corporation and the British Nuclear Forum, at which it was announced that Japan is to spend about $£ 10$ million on research into nuclear steelmaking during the next six years.

Although the meeting left the details of the club-who should be eligible for membership, how much money should be spent and precisely what the objectives should be-to be decided in future consultations, it did provide a useful opportunity for airing the differences between what the steelmakers require of a nuclear power plant and what the nuclear people think they can offer.

One of the basic reasons for the steel industry regarding nuclear power as an attractive source of energy is that the coking-coal now used to produce the coke for blast furnaces is likely to become considerably more costly and scarce in the future. And of the longer term alternatives-such as replacing some of the coke in a blast furnace by oil or natural gas or converting other coals to coke-the most attractive seems to be direct reduction of ore by a hydrogen and carbon monoxide gas.

The so-called reforming stage, at which hydrocarbons are converted into suitable reducing gases, requires heat at $900^{\circ} \mathrm{C}$ or so and this is where a nuclear plant in the form of a High Temperature Reactor (HTR) would come in. Helium coolant at a temperature of about $1,000^{\circ} \mathrm{C}$ could be used as the transfer medium and reducing gases could be produced at a temperature of about $800^{\circ} \mathrm{C}$. This temperature is critical because if the hydrogen is any colder the reduction of ore pellets in the favoured "continuous shaft process"

\section{Nature Subscriptions}

THE Nature subscription list has been computerized. Each address label now carries a reference consisting of three letters and four numbers. Any queries relating to subscriptions should in future quote this reference. can take excessive times and reduction of the pellets may even then not be complete because of reoxidation. (On the other hand, at higher temperatures the ore pellets have to be carefully selected because of the problem of "sticking".)

What do those concerned with HTRs have to say about the problems? Dr L. Shepherd, head of the OECD Dragon HTR project, said that helium temperatures of $1,000^{\circ} \mathrm{C}$ can now be produced for long periods at Dragon with little difficulty and that it should ultimately be possible to raise this by perhaps a few hundred degrees. He went on to say that the design of heat exchangers capable of operating at the temperatures and pressures required seemed to be the most difficult problem. Ceramic exchangers-made, for example, of silicon carbide or silicon nitride-would be

\section{SELECT COMMITTEE}

\section{Science Adviser Likely}

THE Select Committee on Science and Technology may be about to acquire a full-time science adviser. Mr Airey Neave, chairman of the committee, is understood to have approached $\mathrm{Mr}$ James Prior, leader of the House of Commons, asking for his comments on various options put forward by members of the committee.

Although the committee has not discussed the proposal formally as yet, there has been pressure from a number of members for a full-time secretariat. The proposal-if it is accepted-would move the select committee a little nearer the Congressional committee system in the United States where the powerful House committees often have highly qualified secretariats which write and commission background reports for the committees' members.

If $\mathrm{Mr}$ Prior approves the scheme, the science and technology committee will be the first of the select committees to appoint a full-time adviser. Such an appointment would not, however, replace the ad hoc appointments that the committee makes from time to timefor instance it is advised on computer matters by Professor A. Douglas of the London School of Economics.

As the committee has yet to formally consider the proposal and as $\mathrm{Mr}$ Prior has not yet replied to $\mathrm{Mr}$ Neave, the precise role of the adviser has still to be defined. It is unlikely, however, that he lighter and cheaper than metal ones but their performance at high pressures may prove to be a stumbling block.

Another factor that has to be taken into account is that an integrated nuclear steelworks would have to be near a populated area and therefore safety would be a paramount consideration. Because of this, most of the discussions at the meeting assumed that there would be a secondary helium circuit to ensure that radioactive contamination would be minimal. Fortunately the HTR is considered by many to be the safest available reactor type. There is another possibility, however ; reducing gases could be produced with reforming plant at a remote nuclear site and then pumped cold to a steelworks, where they could be reheated by conventional means or by self-burning.

would be an academic scientist. Rather the select committee is likely to look for someone who can find out government attitudes on various matters for the committee.

In line with the select committee's desire to ensure that Mr Heath's government is in fact "open government" it is likely that the correspondence over the appointment of the adviser will be published, if in fact approval for the appointment is given.

Meanwhile the committee is finalizing its reports on nuclear reactor policy and computers. Both will be published in about a month's time, as will the committee's report on the hovertrain. When that appears it is more than likely that Mr Michael Heseltine or, conceivably, Mr Peter Walker, will be invited by the committee to comment on its findings. For a vehicle that no longer runs the hovertrain seems to be an issue with plenty of mileage left in it.

The committee also hopes to finalize its plans to visit Brussels shortly. The visit, originally planned for May, will now take place in the week beginning July 9. It is probable that the committee will take evidence from Commissioners Dahrendorf and Spinelli, as well as from $\mathrm{Mr}$ Christopher Layton, Director for Advanced Technology Industries at the EEC. It is also likely that the select committee will see the commission's directors on energy and nuclear power, and a day visit to Ispra, one of the laboratories of the Joint Research Centre, may be included in the itinerary. 